This electronic prepublication version may contain typographical errors and may be missing artwork such as charts, photographs, etc. Pagination in later versions may differ from this copy; citation references to this material may be incorrect when this prepublication edition is replaced at a later date with the finalized version.

\title{
Phase-Oriented Treatment of Structural Dissociation in Complex Traumatization: Overcoming Trauma-Related Phobias
}

\author{
Kathy Steele, MN, CS \\ Onno van der Hart, $\mathrm{PhD}$ \\ Ellert R.S. Nijenhuis, PhD
}

\begin{abstract}
The theory of structural dissociation of the personality proposes that patients with complex trauma-related disorders are characterized by a division of their personality into different prototypical parts, each with its own psychobiological underpinnings. As one or more "apparently normal" parts (ANPs), patients have a propensity toward engaging in evolutionary prepared action systems for adaptation to daily living to guide their actions. Two or more "emotional" parts (EPs) are
\end{abstract}

Kathy Steele is affiliated with Metropolitan Psychotherapy Associates and Metropolitan Counseling Services, Atlanta, Georgia.

Onno van der Hart is affiliated with the Department of Clinical Psychology, Utrecht University, Utrecht, The Netherlands, and the Sinai Center for Mental Health, Amsterdam, the Netherlands.

Ellert R.S. Nijenhuis is affiliated with the Mental Health Center Drenthe, Assen, The Netherlands.

This article is a revised and updated version of Steele, K., Van der Hart, O., \& Nijenhuis, E.R.S. (2004). Allgemeine Behandlungsstrategien komplexer dissoziativer Störungen: Die Bewältigung traumabezogener Phobien [Phase-oriented treatment of complex dissociative disorders: Overcoming trauma-related phobias]. In A. EckhartHenn \& S.O. Hoffman (Eds.), Dissoziative Störungen des Bewustseins: Theorie, Symptomatik, Therapie [Dissociative disorders of consciousness: Theory, symptoms, therapy] (pp. 357-394). Stuttgart, Germany: Schattauer-Verlag. Permission granted by Schattauer-Verlag.

Address correspondence to: Kathy Steele, MN, CS, Metropolitan Psychotherapy Associates, 1900 Century Place NE, Suite 200, Atlanta, Georgia 30345 (E-mail: kat.steele@comcast.net).

Journal of Trauma \& Dissociation, Vol. 6(3) 2005

http://www.haworthpress.com/web/JTD

(C) 2005 by The Haworth Press, Inc. All rights reserved.

Digital Object Identifier: 10.1300/J229v06n03_02 
fixated in traumatic experience. As EPs, patients predominantly engage action systems related to physical defense and attachment cry. ANP and EP are insufficiently integrated, but interact and share a number of dispositions of the personality (e.g., speaking). All parts are stuck in maladaptive action tendencies that maintain dissociation, including a range of phobias, which is a major focus of this article. Phase-oriented treatment helps patients gradually develop adaptive mental and behavioral actions, thus overcoming their phobias and structural dissociation. Phase 1, "symptom reduction and stabilization," is geared toward overcoming phobias of mental contents, dissociative parts, and attachment and attachment loss with the therapist. Phase 2, "treatment of traumatic memories," is directed toward overcoming the phobia of traumatic memories, and phobias related to insecure attachment to the perpetrator(s), particularly in EPs. In Phase 3, "integration and rehabilitation," treatment is focused on overcoming phobias of normal life, healthy risk-taking and change, and intimacy. To the degree that the theory of structural dissociation serves as an integrative heuristic for treatment, it should be compatible with other theories that guide effective treatment of patients with complex dissociative disorders.[Article copies available for a fee from The Haworth Document Delivery Service: 1-800-HAWORTH. E-mail address: <docdelivery@haworthpress.com> Website: <http://www.HaworthPress. com> (ㄷ) 2005 by The Haworth Press, Inc. All rights reserved.]

KEYWORDS. Dissociation, complex trauma, phase-oriented treatment, dissociative disorders, personality

The major treatment approaches for complex posttraumatic stress disorder (PTSD) and dissociative disorders are typically phase-oriented, and are considered the current standard of care (Brown, Scheflin \& Hammond, 1998; Courtois, 1999; Ford, Courtois, Steele, K., Van der Hart, \& Nijenhuis, in press; Herman, 1992; Horevitz \& Loewenstein, 1994; Huber, 1995; Kluft, 1993a, 1999; McCann \& Pearlman, 1990; Steele, Van der Hart, \& Nijenhuis, 2001, 2004; Van der Hart, 1995; Van der Hart, Van der Kolk, \& Boon, 1998). However, the theoretical basis for such practices remains unclear, partly because of the conceptual confusion involved in a generic model of dissociation (Kihlstrom, 1994; Marshall, Spitzer, \& Liebowitz, 1999; Nijenhuis \& Van der Hart, 1999; Van der Hart \& Dorahy, in press; Van der Hart, Nijenhuis, Steele, $\&$ Brown, 2004). Thus, we first present the evolving theory of structural dissociation of the personality, an integrative heuristic for the full range of trauma-related disorders. We refer the reader to additional sources 
for more in-depth discussions of the theory and explanation of terminology that perhaps may be unfamiliar (cf., Nijenhuis \& Van der Hart, 1999; Nijenhuis, Van der Hart, \& Steele, 2002, 2004a, 2004b; Steele et al., 2001, 2004, in press; Steele, Dorahy, Van der Hart, \& Nijenhuis, in press; Van der Hart, Nijenhuis, Steele, \& Brown, 2004; Van der Hart et al., 1998). This theory provides a conceptual frame for organizing and understanding phase-oriented treatment of trauma-related disorders. Although there is a strong neurobiological underpinning to the theory (e.g., Bremner, 2003; Krystal, Bannett, Bremner, Southwick, \& Charney, 1996; Nijenhuis et al., 2002; Panksepp, 1998; Schore, 2003; Siegel, 1999; Van der Kolk, 2003), as well as burgeoning research that supports the theory (e.g., Nijenhuis, 1999/2004; Putnam, 1997; Reinders et al., 2003, 2003 submitted), these will not be discussed due to space limitations.

The treatment of complex trauma disorders typically draws on an eclectic mix of theories and interventions (e.g., psychodynamic, analytic, ego psychology, cognitive, behavioral, attachment, and neurodevelopmental approaches). Each of these theories attempts to explain the roots of dissociation in a somewhat different way and offers somewhat different treatment approaches. Each has advantages and limitations. The theory of structural dissociation is an evolving integrative theory, rooted in the classical view on dissociation. It integrates major components of other theories and further develops essential concepts, such as a clarified definition of dissociation, specific mental actions that constitute integration; integrative deficits; the role of conditioning effects; the nature and role of action tendencies and action systems in dissociation; and the rigid and maladaptive interactions among dissociative parts. The theory of structural dissociation can be applied consistently across the entire spectrum of trauma-related disorders, and is based on the original phase-oriented model found in Pierre Janet's pioneering work (Janet, 1898, 1919/25; cf. Van der Hart, Brown \& Van der Kolk, 1989). Phase-oriented treatment distinguishes the following phases: (1) stabilization and symptom reduction, (2) treatment of traumatic memories, and (3) personality integration and rehabilitation. In this article we focus on how the theory specifically applies to trauma-related phobias.

Following our theory and in harmony with Janet's view, the goals for each treatment phase can be partially expressed in terms of mental actions that are intended to overcome specific trauma-related phobias that maintain dissociation and prevent integration (Janet, 1904, 1919/ 25). Traditionally, phobias have been relegated to anxiety disorders, and have been understood to be directed generally to external phenom- 
ena (e.g., phobia of spiders, heights, germs, social phobia), and to have psychodynamic meaning. However, more than a century ago Janet (1903) made it abundantly clear that phobias can also be directed toward internal experiences such as thoughts, feelings, fantasies, sensations-a view confirmed by our own and other's observations and theoretical understanding (e.g., McCullough et al., 2003; Nijenhuis, 1994; Van der Hart, Steele, Boon, \& Brown, 1993). Clinicians who work with chronically traumatized individuals will readily recognize that such patients are often extraordinarily fearful of internal mental contents as well as external cues that serve as reminders of the trauma. Though inner directed phobias certainly may have psychodynamic meaning which should be understood by the clinician, they also result from fundamental skills deficits such as affect regulation and mentalization (e.g., Fonagy, Gergely, Jurist, \& Target, 2002; Schore, 2003; Siegel, 1999). These skills are developmental achievements requiring adequate dyadic regulation and secure attachment in early childhood that many chronically traumatized individuals did not receive (e.g., Fonagy et al., 2002; Forrest, 2001; Schore, 2003). According to Janet, the core phobia in trauma-related structural dissociation consists of an avoidance of full realization of the trauma and its effects on one's life (i.e., the phobia of traumatic memory). Increasing behavioral and mental avoidance, which maintains structural dissociation, is needed to prevent what are perceived as unbearable realizations about one's self, history, and meaning. Subsequently, ever encompassing phobias ensue from the fundamental phobia of traumatic memory, including phobias of other mental contents and dissociative parts. Overcoming this complex of phobias is essential to successful treatment.

Janet (1909) stated that all phobias have in common fears of (certain) actions. Trauma-related phobias are thus treated in a specific order such that patients experience a gradually developing capacity to engage in purposeful and high quality adaptive actions, both mental and physical. Increasingly more complex and difficult experiences (past and present) then can be tolerated and integrated, and improvement in daily living can be achieved.

\section{THE THEORY OF STRUCTURAL DISSOCIATION}

For more than 150 years, clinicians have observed a specific pattern of recurrent alternations in traumatized individuals of the re-experience of traumatic memories (PTSD criterion B, APA, 1994) and numbing 
and avoidance of these memories (PTSD criterion C) (e.g., Breuer \& Freud, 1893; Brewin, 2003; Janet, 1904; Kardiner, 1941; Myers, 1940; Nijenhuis \& Van der Hart, 1999; Van der Kolk \& Van der Hart, 1991). This symptom pattern constitutes the foundation of the diagnosis of posttraumatic stress disorder (PTSD; APA), and is present in most trauma-related disorders. We propose that the psychophysiological differences between intrusion on the one hand, and avoidance, numbing and detachment on the other hand, characterize two prototypical parts of the personality that have become structurally dissociated from each other. Each dissociative part of the personality has an evolutionary based predilection toward a limited and rather rigid set of action tendencies that may be in conflict with the tendencies of other parts, and such tendencies are often maladaptive. These maladaptive actions or lack of actions are symptoms of, and also maintain, dissociation.

Each dissociative part often seeks incompatible goals in the life of the trauma survivor and remains in (potential) conflict with other parts. One or more parts become fixed in traumatic memory and "live" in the past, unable to experience much, if any, of the present. These parts have an attentional bias for perceived threat cues. Paradoxically, one or more parts are fixed in trying to live a normal life while avoiding traumatic memories, thus exhibiting the primary phobia of traumatic memories.

In conceptualizing these prototypical dissociative parts of the personality, we take as a point of departure a little-known but important work of the British World War I psychologist, Charles Samuel Myers (1940), who described a basic form of structural dissociation in acutely traumatized ("shell-shocked") World War I combat soldiers (cf., Van der Hart, Van Dijke, Van Son, \& Steele, 2000). This dissociation involves the co-existence of and alternation between a so-called Emotional [Part of the] Personality (EP) which is fixated in one or more traumatic memories and focused on the detection of threat, and a so-called Apparently Normal [Part of the] Personality (ANP) which is fixated in trying to go on with normal life while being phobically avoidant of one or more traumatic memories, manifesting in degrees of detachment, numbing, depersonalization, and partial or complete amnesia.

\section{Primary Structural Dissociation}

Primary structural dissociation is a basic division of the personality into a single ANP and a single EP. It appears to characterize simple trauma-related disorders, including PTSD. We emphasize the word 
"structural," because trauma-related dissociation does not occur at random but likely follows rather well-defined evolutionary prepared metaphorical "fault lines" in the structure of the personality, a view we develop below. More complex forms of structural dissociation, described below in terms of secondary and tertiary structural dissociation and involve wider ranges of dissociative parts, are variations on this primary structural dissociation of the personality.

Like many other authors (e.g., McDougall, 1926), Myers used the term "personality," which we find overly inclusive, so we have changed his term to "part of the personality." This is a term with which traumatized patients seem to resonate. Dissociative parts of the personality, however more or less autonomous and elaborated, are still components of a single personality. The parts have both insufficient integration and some degree of psychobiological overlap. They may also share a number of dispositions, and implicit and explicit memories.

Each dissociative part of the personality can be considered a (sub)system of the personality, following the ideas of systems theory (Benyakar, Kutz, Dasberg, \& Stern, 1989). Dissociative parts have been unable to master the dialectical tension between stability and flexibility (i.e., ideal adaptation). Each has a comparatively rigid and somewhat limited set of action tendencies based on the inclusion of particular goals and the exclusion of other goals, and thus can be viewed as a relatively closed (sub)system. Yet, they are not completely separate or static, but change and interact within some limits, albeit in rather inflexible and uncoordinated ways. Thus they should not be considered completely closed or fixed structures. While there are clear and specific treatment implications for dissociative parts of the personality, treatment is always directed toward the whole person (Kluft, 1999). Even though we work with individual parts at times, our interventions remain directed primarily toward the interactions among parts (i.e., toward the personality system as a whole).

\section{Actions Systems and Structural Dissociation}

Although the personality can, in principle, become dissociated in countless ways, some forms of trauma-related structural dissociation appear to be much more likely than others. The theory of structural dissociation proposes that since individuals are significantly mediated and motivated by evolutionary prepared, psychobiological systems (Barkes, Cosmides, \& Tooby, 1992; Gould, 1982; Lang, Bradley, \& Cuthbert, 1998; Panksepp, 1998), all dissociative parts of the personality will be 
as well. These systems are sometimes referred to as motivational (e.g., Gould, 1982; Lichtenberg, 1990; Lichtenberg \& Kindler, 1994), behavioral (e.g., Bowlby, 1969/1982; Cassidy, 1999), functional (Fanselow \& Lester, 1988), emotional operating systems (Panksepp, 1998), or adaptations (Barkes et al., 1992). Their purpose is to help us distinguish between helpful and harmful experiences, and to generate the best adaptive responses to current life circumstances. We refer to them as action systems, because they involve an innate readiness or tendency to act (Arnold, 1960; Frijda, 1986). They do not rigidly determine actions, but influence tendencies toward particular action patterns under particular circumstances. These actions have a highly predictive quality: We predict a goal and act accordingly (e.g., Sudakov, 2004). Thus, in a given situation each dissociative part of the personality has a propensity to exhibit a particular pattern of behaviors, thoughts, feelings, sensations, and perceptions that may differ significantly from other parts, based on the action systems by which each is influenced. Thus, various parts are constrained to some degree by the specific action systems by which they are mediated, leading to relatively inflexible mental and physical actions.

There are two basic categories of actions systems (Lang et al., 1998). The first category promotes functioning in daily life and survival of the species, and the second promotes defense (and survival) of the individual in the face of threat. Metaphorically speaking, fault lines occur between action systems of daily life and those of defense, because they naturally tend to mutually inhibit each other. For example, one does not stay focused on cleaning the house or reading when imminent danger is perceived; instead one becomes hypervigilant and prepares for defense. Then, when danger has passed, one should naturally return to normal activities rather than continuing to be in a defensive mode. Integration between these two types of action systems will more likely fail during or following traumatic stress than will integration among internal components of each of these two complex action systems.

We propose that the basic dissociative division between the two main categories of action systems, daily life and defense under threat, primarily accounts for the prototypical organizations of ANP and EP. In other words, dissociation between action systems of daily life and of defense is a reasonable explanation for the alternating dissociative pattern of numbing and intrusions in trauma-related disorders. Action systems that control functions in daily life belong to the ANP, whose task is to continue to go on with life in spite of traumatization, in part by avoiding traumatic memories. Some of the functions of the ANP include explora- 
tion of the environment (including work and study), play, energy management (sleeping and eating), attachment, sociability, reproduction/ sexuality, and care taking (especially rearing of children) (e.g., Cassidy, 1999; Panksepp, 1998). Other higher order actions than those prepared by evolution often develop through higher cortical functioning (e.g., playing the piano, driving a car, operating a computer, engaging in extremely complex social and work interactions; Hurley, 1998).

The EP remains fixed in traumatic memories, and thus in the action system of defense, which includes several subsystems. The first subsystem, mediated by panic (Panksepp, 1998), is the attachment cry, which is a desperate call for closensess and reconnection with a caregiver. Children thus cry for their caregivers when they are scared, and patients often pick up the phone and call their therapist. Other defensive subsystems include hypervigilance, flight, freeze with analgesia, fight, total submission with anesthesia (collapse), and recuperative states of rest, wound care, isolation from the group, and gradual return to daily activities (i.e., to the action systems of daily life) (Fanselow \& Lester, 1988; Nijenhuis, 1999/2004). The EP is typically fixed in one or more of these subsystems of physical defense, in addition to engaging in psychological defenses in the case of more elaborated EPs. This fixation includes predicting threat in the light of previous traumatization and responding in a rigid, often maladaptive way. Links have been demonstrated between these animal defensive reactions and physical manifestations of dissociation in humans such as analgesia, anesthesia, motor inhibitions and paralysis (Nijenhuis, Spinhoven, P., Vanderlinden, Van Dyck, \& Van der Hart, 1998; Nijenhuis, Van der Hart \& Steele, 2004a, 2004b).

When an individual is dissociative, there is insufficient cohesion and coordination among action systems which are essential components of the personality. Thus, even though no danger is present, the EP will act as though there is, and the ANP attempting to cope with daily life will be inhibited.

\section{Secondary Structural Dissociation}

When trauma is increasingly overwhelming and/or prolonged, further division of the EP may occur, while a single ANP remains intact. This secondary structural dissociation may be based on the failed integration among separate defense and recuperative subsystems. We consider instances of secondary structural dissociation to be included in complex trauma-related disorders, such as complex PTSD (Disorders of Extreme Stress Not Otherwise Specified [DESNOS]), trauma-related 
borderline personality disorder, and dissociative disorders not otherwise specified (DDNOS) (cf., Blizard, 2003). With the exception of the major part (i.e., the ANP), which functions in daily life most of the time, the EPs found in primary and much of secondary structural dissociation are typically not very elaborated or autonomous.

\section{Tertiary Structural Dissociation}

Finally, division of the ANP may also occur. This tertiary structural dissociation occurs when certain inescapable aspects of daily life have become associated with past trauma (i.e., triggers that tend to reactivate traumatic memories through the process of generalization learning). Alternately when the functioning of the ANP is so poor that normal life itself is overwhelming, new ANPs may develop. These may be based on perhaps only a single action systems, such as caretaking (e.g., the mother), or exploration (e.g., the worker. Tertiary structural dissociation includes division of the ANP in addition to the EP, and we propose reserving this level of structural dissociation exclusively for patients with dissociative identity disorder (DID). In severe cases of secondary and in all cases of tertiary dissociation, more than a single part will have a strong degree of elaboration and autonomy, often with secondary characteristics such as names, ages, gender, etc.

\section{Developmental Pathways to Structural Dissociation}

In primary structural dissociation we have assumed that the personality was a relatively integrated mental system prior to traumatization. However, this is hardly the case in traumatized children. An integrated personality is a developmental achievement. The more complex levels of structural dissociation in adults who were chronically traumatized children are thus developed within a personality that lacks the normal cohesion and coherence of the healthy adult. The complexity of structural dissociation seems linked to interactions among (1) developmental level, age, and related integrative capacity of the individual (e.g., Ogawa, Sroufe, Weinfield, Carlson \& Egeland, 1997; Putnam, 1997); (2) severity and duration of traumatization (e.g., Brewin, Andrews, \& Valentine, 2000); (3) presence of peritraumatic dissociation (e.g., Marmar, Weiss, \& Metzler, 1998); (4) family history of psychopathology (e.g., Ozer, Best, Lipsey, \& Weiss, 2003); (5) degree of social support (e.g., Ozer et al., 2003); (6) disruption of the normal integration of the child's action systems that requires a secure attachment relationship (e.g., 
Siegel, 1999); (7) genetic factors (e.g., Becker-Blease et al., 2004); and (8) resilience factors (e.g., McGloin \& Widom, 2001). Although these cannot be discussed in depth here, we make several observations that form the basis of contemporary thought regarding how dissociation in young children becomes a chronic condition.

Structural dissociation involves hindrance of a natural progression toward integration of action systems that have been described as discrete behavioral states (Putnam, 1997; Siegel, 1999). It involves a chronic integrative deficit largely due a combination of the child's immature integrative brain structures and functions (cf., DeBellis, 2001; Glaser, 2000; Van der Kolk, 2003), and inadequate dyadic regulation.

The sense of self is still highly state-dependent in the infant (Wolf, 1990; Wolff, 1987), and it is within positive and secure dyadic interaction with caretakers that children acquire skills to sustain, modulate, and integrate discrete behavioral states (e.g., Putnam, 1997; Siegel,1999; Schore, 2003) that would lead to a relatively integrated personality. Under these conditions, neural networks related to daily life action systems become increasingly more complex and interactive through constant and consistent use, leading to a more cohesive personality and an individual who is well adapted to life with others (Lyons-Ruth, 2003).

Research and clinical observations have shown a strong link between disordered parental attachment, disorganized/disoriented attachment in the child, and chronic dissociation (Barach, 1991; Carlson, 1998; Liotti, 1992, 1999; Lyons-Ruth, 2003; Ogawa et al., 1997). Young children's innate attachment system evokes mental and behavioral approach when they are separated from their caregiver. However, a frightening parent evokes a succession of defensive subsystems in the child (flight, freeze, fight, submission, and total collapse). We argue that disorganized attachment is not actually disorganized. The conflict between approach and avoidance that cannot be resolved by the child promotes a structural dissociation between parts fixed in various attachment actions or in defense actions that conflict with each other. Another way to say this is that attachment and defense systems are organized within parts, but are not cohesive across parts.

Chronically traumatized individuals often display a lack of self-regulatory skills, both mental and behavioral. These include skills such as mindful awareness; interpersonal competence; affect regulation; distress tolerance; ability to differentiate between internal and external reality; ability to tolerate aloneness; ability to regulate self-conscious emotions (e.g., self-hate, shame, guilt, humiliation); ability to selfsoothe; the ability to reflect more than merely react; and ability to 
mentalize (i.e., imagine how others might think or feel; e.g., Fonagy \& Target, 1997; Gold, 2000; Linehan, 1993). When these essential skills are deficient or absent, integration becomes ever more difficult to achieve or maintain, contributing to chronic structural dissociation.

The survivor's personality as a whole and the various dissociative parts thus engage in dysfunctional behaviors, and the tendency to integrate the different action systems remains insufficient. Consequently, survivors engage in maladaptive patterns of living and in psychophysiological dysregulation, such as impaired sleep/wake cycles; eating difficulties; problems with sociability and work; affect and impulse dysregulation; imbalances between work, rest, and play; and limitations in learning and in exploring the world. Survivors will substitute less adaptive, lower-level actions in an effort to compensate for their deficits. Rather than being reflective, these substitute actions (Janet, 1928b, 1945) are typically impulsive, conditioned reactions, such as self-harm, substance abuse, or inappropriate relational strategies, and they are the basis of much psychopathology. We propose that Axis II difficulties reflect chronic dysfunctional action tendencies, often characteristic of specific dissociative parts.

\section{Mental Coping Strategies and Dissociation}

Clinically, therapists can often observe various parts of the personality engage in what are known in the literature as psychological defenses, such as disowning of affect, projection, denial, or splitting. Because our theory focuses on both mental and behavioral actions and distinguishes between psychological and physical defenses, we use the term mental coping strategies. The trauma literature is replete with theories and treatments of these various mental coping strategies, and dissociation has been understood widely as a mental defense against the intolerable affects and experiences of trauma (e.g., Blizard, 2001; Cardeña, 1994; Chu, 1998; Freyd, 1996; Spiegel, 1990). However, we emphasize that dissociation is first a deficit in integrative capacity, and only secondarily a mental coping strategy. The less integrative and reflective individuals are, the more they must rely on rigid, maladaptive mental actions, including the more "primitive" ones such as projection, splitting, disavowal, denial. Such coping strategies protect against inner directed phobic responses. When maladaptive mental coping strategies are dissociated within parts of the personality they become inaccessible to modification without proper treatment interventions, leaving the 
individual as a whole vulnerable to chronic dysfunction in life and relationships.

ANP may "use" EPs as mental protection, in that they contain emotions, thoughts, fantasies, wishes, needs, sensations, etc., that the ANP believes to be unbearable or unacceptable. ANPs may disown dependency needs through EPs that are commonly fixed in attachment cry and seeking attachment desperately (Steele et al., 2001). Even parts who appear on the surface to be conflict free, such as parts whose only function is to do math, are typically well-defended against attachment, for example, and see it as entirely irrelevant, much like a schizoid person might.

A number of clinicians have noted that chronically traumatized patients, particularly with DID, have varying levels of functioning, low, medium, or high, that predict to some degree the success of treatment (Boon, 1997; Horevitz \& Loewenstein, 1994; Kluft, 1994c; Van der Hart \& Boon, 1997). Depending on the degree of action system dysfunction and which action systems are affected, some ANPs may be much less functional than others, and such patients will require much more time to acquire additional skills and healthy action patterns.

\section{STRUCTURAL DISSOCIATION AND INTEGRATIVE CAPACITY}

A healthy personality is characterized by a strong capacity to integrate experience (Janet, 1889). Integration is an adaptive process involving ongoing mental actions that help both to differentiate and link experiences over time into a flexible and stable personality that promotes the best functioning possible in the present (Jackson, 1931/32; Janet, 1889; Meares, 1999; Nijenhuis et al., 2004a, 2004b). The capacity to be open and flexible allows us to change when required, whereas the capacity to stay closed allows us to remain stable (i.e., to act in preconceived ways). In structural dissociation, although parts are not completely static or closed, there is insufficient linking and coordination among them. Thus, the entire personality of the traumatized individual is too closed and rigid in fundamental ways, leading to proliferation of relatively stereotypical and poorly coordinated actions within and among various dissociative parts.

\section{Synthesis}

Several types of integrative mental actions need to be understood in order to most effectively treat traumatized individuals. One major type 
is synthesis (i.e., linking/binding) and differentiating a range of internal and external experiences at a moment and across time. Synthesis includes linking and differentiating sensory perceptions, movements, thoughts, affects, and sense of self. It is a dimensional construct, and the capacity to synthesize oscillates. For example, when an individual is fully awake, synthesis will be of a higher quality than when s/he is tired. Synthesis provides for the individual's normative unity of consciousness and history. Alterations of consciousness and dissociative symptoms can emerge when synthesis is incomplete.

\section{Realization}

Another related, but higher level integrative mental action is realization (i.e., the degree to which individuals become consciously aware of the implications and meaning of their personal experiences). Realization implies the degree to which closure of an experience is achieved (Janet, 1935; Van der Hart et al., 1993). It consists of two mental actions that are constantly maturing our view of ourselves, others, and the world: personification (Janet, 1903) and presentification (Janet, 1928a). Personification involves integrating the synthesis of an experience with an explicit, personal sense of ownership: (e.g., "That happened to me, and I think and feel thus and so about it"). Presentification is the mental action of being firmly grounded in the present and integrating one's personified past, present, and future. It manifests in acting in the present in the most adaptive, mindful manner.

Both ANP and EP lack full realization of the trauma. ANP lacks personification of the traumatic experience and its aftereffects. Thus ANP may deny or experience varying degrees of amnesia regarding the event(s). ANP perhaps acknowledges trauma but insists, "It doesn't feel like it happened to me." EP does not experience that the trauma has ended, and thus lacks presentification, the ability to be fully in the present. Restricted by their respective action systems, both ANP and EP selectively attend to a limited range of cues (e.g., those that are relevant for care taking or defensive interests). This further reduces the capacity to fully realize and integrate trauma and to be completely in the present.

\section{Traumatic Memory versus Autobiographical Narrative Memory}

An important notion related to structural dissociation and integrative mental actions is that of traumatic versus autobiographical narrative memory. Janet (1928a) noted that normal memory consists of two sets 
of action: (1) the actions during the event itself, and (2) an account of the event that symbolizes the past actions afterwards. This dual action should take place within the personality as an integrative process. However, the EP is fixated in the first part of the action, as it recurrently reexperiences a primarily sensorimotor, highly affectively charged experience of the trauma (Janet, 1919/25; Nijenhuis \& Van der Hart, 1999; Van der Kolk \& Fisler, 1995; Van der Kolk \& Van der Hart, 1991). Brewin has referred to this traumatic memory as situationally accessible memory (SAM; Brewin, 2003), which is evoked by triggers rather than accessed verbally and consciously. The ANP avoids giving an account of the trauma, or develops an account without full personification. Over the course of treatment traumatic memories must be transformed into narratives, by gradually realizing and integrating the trauma as a past event in one's "autobiography," thus alleviating structural dissociation (Janet, 1928a; Van der Hart et al., 1993). Brewin has called this verbally accessible memory (VAM; Brewin, 2003), and new VAM will inhibit SAM, which remains in existence.

\section{MAINTENANCE OF STRUCTURAL DISSOCIATION OF THE PERSONALITY}

The various trauma-related phobias generally result from conditioning effects related to traumatization (Nijenhuis et al., 2004a, 2004b; Steele et al., 2004), and from maladaptive action tendencies that developed due to poor modeling, inadequate dyadic regulation, and lack of basic skills.

Via classical conditioning, the traumatized individual associates experiences that saliently signaled or accompanied the traumatizing event with the traumatic experience itself. As a result, previously neutral cues (e.g., a man with a beard) will tend to evoke memory, perhaps only in somatosensory form, of the traumatic event and the original traumatic reaction pattern. For example, the specific affect of an abusive caretaker (e.g., rage) will probably become a conditioned stimulus, as will stimuli

that apparently seemed to elicit this mood. The survivor may then rather automatically respond by fighting, freezing, or collapsing when confronted by another person who expresses the same or similar affect. 
Phobias of Traumatic Memories, Mental Contents, and Dissociative Parts of the Personality

Structural dissociation is not absolute. For example, when an EP is strongly reactivated by conditioned stimuli that evoke traumatic memories, it may intrude into ANP. These unintegrated, highly affectively charged experiences are inherently aversive to the ANP. Thus, ANP will often respond to intrusions with typical mental avoidance and escape reactions: extreme and involuntary retraction of the field of consciousness and ongoing dissociation of the EP. This extreme avoidance reaction to EP and related traumatic memories is called the phobia of traumatic memory (Janet, 1904; Van der Hart et al., 1993), and is treated in Phase 2. In this way the ongoing effects of classical conditioning support continued structural dissociation (Nijenhuis et al., 2004a, 2004b).

The phobia of mental contents (Van der Hart \& Steele, 1999), treated in Phase 1, may develop along two pathways. This first involves developmental deficits in mentalization and affect regulation. Without adequate mentalization the traumatized individual has difficulty with understanding or dealing with mental contents. Feelings, needs, fantasies, etc., remain partially or completely unintegrated, and become feared and confusing aspects of self.

Second, some aversive mental contents are typically held in particular parts of the personality that become feared in themselves. For example, the ANP learns to fear and vehemently avoid internal (mental contents) and external stimuli related to the EP holding the trauma. Specifically, a phobia of dissociative parts of the personality (Nijenhuis, 1994) will develop, which is primarily treated in Phase 1 . These conditioned reactions of the ANP interfere with the normal integrative tendencies of the mind, and thus maintain structural dissociation of the personality.

Phobias are not only based on fear, but also on conditioned negative evaluations. ANPs and EPs often avoid and escape from each other because they dislike each other and associated traumatic memories. For example, one part may be deeply ashamed of the feelings or behaviors of another part. Some EPs dislike ANP because they report that "she doesn't care," as ANP assiduously avoids the pain of the EP.

There is a wide range of avoidance and escape reactions regarding traumatic memories, dissociative parts, mental contents, and attachment and attachment loss. They include passive and active behavioral actions. In cases of secondary and tertiary dissociation, EPs and ANPs 
may learn to fear, despise, and avoid each other along similar pathways. For example, the EP that encompasses freezing and analgesia may come to fear and avoid the EP that involves aggression, in particular when this aggression becomes self-directed. And this "aggressive" EP may fear, avoid, and despise the freezing one, as well as the submissive one, because of their "weakness" which "makes them guilty of causing the trauma."

\section{Phobias of Attachment and Attachment Loss}

Human induced trauma has the potential to severely affect the action system of attachment. In fact, several authors regard disordered attachment as central to complex dissociative disorders (e.g., Barach, 1991; Blizard, 2003; Liotti, 1992, 1999; Lyons-Ruth, 2003). Because attachment is experienced as dangerous when one has been hurt recurrently by known and trusted others, an eventual phobia of attachment and intimacy may develop. Thus, phobia of attachment and attachment loss with the therapist is specifically addressed with the ANP in Phase 1, while phobia of attachment with others is also treated in all phases.

Phobia of attachment is often paradoxically accompanied by an equally intense phobia of attachment loss. Phobia of attachment loss is driven by panic and the attachment cry defense action (sub)system. It manifests in desperate attempts at connection, pleading, clinging, crying, xtreme helplessness, and even self-harm or suicidal behavior in response to perceived attachment loss. Typically, deifferent parts of the personality experience these opposite phobias. They evoke each other in a vicious cycle, with a perceived change in closeness or distance in a relationship resulting in the well-known "borderline" pattern of "I hate you-don't leave me," otherwise more recently described as D-attachment.

Abuse and neglect from a primary caretaker lead to proximate activation of approach and defensive systems directed toward the caretaker/ perpetrator. There remains intense attachment to and fear of the perpetrator. Thus, there are also phobias of attachment and attachment loss to the perpetrator (treated primarily in Phase 2). Such phobias prevent secure attachment with others until they are resolved, and also prevent realization of the trauma. As one patient said, "I loved my father AND he hurt me. I've never been able to put those two ideas together in a sentence before. It was intolerable because my love for him was essential to my survival." 
Phobia of Normal Life, Healthy Risk-taking, Change, and Intimacy

Because there are ever increasing stimuli that become conditioned through stimulus generalization, more and more of life may become avoided by the traumatized individual. Thus, patients develop a phobia of normal life. Since normal life involves at least a basic level of healthy risk-taking and change, these experiences of normal life also become vigorously avoided. Finally, more mature levels of attachment (i.e., intimacy) are avoided due to the plethora of other phobias related to attachment and internal states that have become conditioned stimuli. These phobias of normal life, of healthy risk-taking and change, and of intimacy are recursively addressed throughout therapy, but are a primary target in Phase 3.

\section{PHASE-ORIENTED TREATMENT OF STRUCTURAL DISSOCIATION}

The theory of structural dissociation guides the clinician in treatment planning and interventions (Steele et al., 2001, 2004). In all cases, therapeutic effort must first be directed to raising the integrative capacity of the ANP and key EPs that are intrusive and/or interfering with therapy and safety concerns. This implies that survivors must improve the reflective quality and sometimes quantity of their mental and physical actions. This is relatively straightforward in cases of primary structural dissociation within the context of short-term psychotherapy (Van der Hart et al., 1998). However, in cases of secondary and tertiary structural dissociation typically much more strenuous and long-term therapeutic effort must be invested in raising the integrative capacity of the ANP(s) and certain dominant EPs before the treatment of traumatic memories can ever be considered.

Although the phases (see Table 1) have been described in linear fashion, in reality they are flexible and recursive, involving a periodic need to return to previous phases (Courtois, 1999). Each phase involves a problem-solving and skills building approach within the broader context of a relational approach (Brown, Scheflin \& Hammond, 1998). This spiral course occurs as greater levels of integrative capacity are achieved, allowing previously intolerable dissociated material to become integrated, and more entrenched areas of dysfunction to be addressed. 
TABLE 1. Phase-oriented Treatment of Trauma: Overcoming Trauma-related Phobias

Phase 1: Symptom reduction and stabilization

- Overcoming the phobia of attachment and attachment loss with the therapist

- Overcoming the phobia of mental contents

- Overcoming the phobia of dissociative parts of the personality (ANP and EP)

Phase 2: Treatment of traumatic memories

- Overcoming the phobias related to insecure attachment to the perpetrator(s)

- Overcoming the phobia of attachment and attachment loss with the therapist in EPs

- Overcoming the phobia of traumatic memories

Phase 3: Integration and rehabilitation

- Overcoming the phobia of normal life

- Overcoming the phobia of healthy risk-taking and change

- Overcoming the phobia of intimacy

\section{Treatment Principles Throughout Phase-Oriented Treatment}

The most general objective of therapy is to raise the patient's integrative capacity to improve functioning and resolve structural dissociation and related maladaptive behaviors (Steele et al., 2004). During this process, the various trauma-related phobias will be addressed.

First, psychophysiological arousal levels must be monitored and controlled, keeping arousal within a window of tolerance for the patient. This window is defined by the upper and lower levels of arousal that still allow for adaptive actions of sufficient quality, including integration of experiences and daily functioning. Hyperarousal occurs when integrative capacity is not sufficient to allow integration of stressful stimulation. It manifests as panic (vehement emotions and reflexive actions), sustained structural dissociation, and an overly narrow field of consciousness. Hypo-arousal (e.g., due to physical and mental exhaustion), as well as mental avoidance strategies, involve a (very) low level of consciousness that hampers adequate perception and further processing of stimuli. These low levels, often confused with dissociation (Van der Hart et al., 2004), manifest as daydreaming, trance states, loss of concentration, inability to complete actions, etc.

Second, the capacity to function in normal daily life must be maintained and improved. This will involve increasing the capacity to modulate and coordinate action systems. The therapist must, at least initially, provide dyadic modulation of the patient's emotional reactions, and assist the patient in developing or strengthening his or her own capacities 
in this regard by modeling, instruction, rehearsal, and homework assignments. In other words, coordinated and flexible functioning of different action systems must be achieved.

Third, associations between conditioning effects must be extinguished while preventing structural dissociation and other avoidant behaviors. For example, patients must learn that only some, not all, human beings pose a threat, and that emotions that were intolerable to a traumatized child can be tolerated as an adult who survived trauma and who can be supported. This contextual learning results from gradual and controlled re-exposure to conditioned stimuli related to the trauma, and to all the resulting phobias.

Fourth, psychoeducation and skills training are employed where knowledge and skills are lacking, when beliefs are at odds with reality, and ways of acting are ineffective or harmful to the patient or others. Some skills development will be the result not only of training, but of the consistent dyadic regulation of the therapeutic relationship. These skills allow for increasing development and coordination of action systems, resulting in more adaptive coping.

Fifth, transference and countertransference responses must be meticulously managed. Although it is beyond the scope of this paper to provide in-depth discussion of transference and countertransference, the clinician must have a thorough working knowledge of them, and the particular, complex, and contradictory ways in which they manifest in traumatized patients and their clinicians. A few essential publications include Allen, 2001; Chu, 1998; Dalenberg, 2000; Davies \& Frawley, 1994; Kluft, 1994b; Loewenstein, 1993; Pearlman \& Saakvitne, 1995; Wilson \& Lindy, 1994; Wilson \& Thomas, 2004. The psychodynamic, analytic, and object relations literatures are particularly helpful in understanding complex and difficult countertransference and transference problems.

From the viewpoint of the theory of structural dissociation, countertransference and transference and phenomena are essentially the result of low levels of integrative capacity in the clinician, the patient, or both. They are often related to attachment insecurity, projective identification, inability to mentalize, and boundary confusions. The therapist's lowered integrative level and lack of realization of personal issues can potentially interfere with therapy. The therapist must have sufficient integrative ability to remain fully present and clearly think through interventions, to retain a gestalt of the entire system of dissociated parts of a single personality and their conflicts so that interventions, including use of the relationship, can be thoughtfully balanced. In the same vein, 
transference is the result of unresolved historical interpersonal issues and lack of mentalization, and requires increasing levels of integrative capacity to resolve.

\section{TREATMENT PHASE 1: STABILIZATION AND SYMPTOM REDUCTION}

Treatment in Phase 1 is directed to overcoming the phobia of attachment and attachment loss with the therapist, the phobia of mental contents, and of dissociative parts of the personality. Treatment begins with the $A N P(s)$ and those EPs that are intrusive and interfering with therapy regarding these phobias. Only when these phobias have been substantially reduced in the $A N P(s)$ and in EPs that are imminently impinging on safety or therapeutic progress can the phobia of traumatic memories be addressed in Phase 2.

Promotion of daily life functioning in the ANP involves decreasing or eliminating debilitating symptoms of depression, anxiety, and PTSD, including undue reactivations of EPs and traumatic memories. In addition, self-destructive thoughts and actions such as self-harm, suicidality, substance abuse, violence, and risky behaviors must be aggressively treated in Phase 1. A maxim of treatment is always safety first. Skills to diminish or eliminate self-destructive tendencies include the ability to tolerate and modulate emotions and physiological arousal.

More specifically, these skills consist of experiencing emotion (e.g., anger, fear, shame, loneliness) and arousal (palpitations, sweating, etc.) while quelling the impulse to automatically react in maladaptive ways (i.e., with substitute actions). Skills also pertain to modulation of internal states through, for example, self-soothing, seeking help from trusted friends (Linehan, 1993; McCann \& Pearlman, 1990), and engaging in a secure therapeutic relationship. For example, the therapist can frequently ask about and observe bodily reactions and non-verbal behaviors to determine whether the patient is becoming overly aroused, and immediately stop what is being done or discussed, and focus on helping the patient regulate his or her arousal level (Ogden \& Minton, 2000; Rothschild, 2000).

Behavioral rehearsal of positive resources (e.g., relaxation skills, structuring daily activities, energy management, promotion of somatic resources such as grounding, and facilitation of expressive movements; Ogden \& Minton, 2000 are helpful in this phase). The installation of positive resources with techniques such as EMDR (e.g., Gelinas, 2003; 
Twombly, 2000) and hypnosis may be useful in providing ego support. However, both techniques, even if only used for ego strengthening, should only be utilized by therapists specifically trained in their application to chronically traumatized individuals. Patients can also learn containment imagery (Brown \& Fromm, 1986; Kluft, 1993a; Van der Hart et al., 1993) that enables them temporarily to "store" traumatic memories or other threatening material, helping them to learn the difference between avoidance, and healthy pacing and timing that is within their control.

These combined skills raise integrative capacity by providing increasing competence in daily life, and thus will allow the ANP to gradually approach internal aversive stimuli without re-dissociation, retraction of the field of consciousness, or drops in the level of consciousness. In positive terms, Phase 1 is dedicated toward raising the integrative capacity of the ANP(s) and dominant EPs to allow for more effective functioning in daily life. The patient must gradually develop empathy for and enhanced cooperation among all parts of the personality, without yet sharing traumatic materials. First, skills that promote increasing attentiveness (mindfulness; Linehan, 1993) to the internal and external environments are essential, including acknowledgement of the existence of EP(s) and conflicting interests among various parts of the personality. This involves the development of a complex theory of mind; space limitations preclude a full discussion of this process. However, awareness is not sufficient by itself. It must be accompanied eventually by adaptive actions. Phase 1 treatment also promotes recognition of external and internal conditioned stimuli (triggers), the evocation of EPs (defense action systems) that result from triggers, and modulation of responses to these cues. When these, and related goals have been reached, it becomes possible to move forward with Phase 2 treatment.

\section{Overcoming the Phobia of Attachment and Attachment Loss with the Therapist}

The ANP typically will approach the therapist, asking for help with distressing symptoms. Some ANPs will be avoidant of attachment, while others will not. But regardless of the attachment style of the ANP, other EPs may look upon the therapist as a potential (substitute) caretaker so that attachment loss can be avoided, while some defensive EPs will fear and avoid the therapist because proximity to a caretaking figure is a conditioned stimulus for neglect and abuse. Thus begins the approach/avoidance struggle so common in the therapeutic relationship. 
A growing sense of secure attachment with the therapist as a result of predictable, controlled and benevolent therapeutic interaction will help the ANP(s) to learn to attend to internal states and regulate reaction patterns. However, increase in attachment in the ANP must be well paced, as premature movement towards "too much" attachment will evoke overwhelming and aversive internal stimuli that may exceed the patient's window of tolerance (e.g., dependency yearning held in EPs, or EPs that are rageful toward the therapist). The therapist must remain alert to the fact that both attachment and attachment loss are feared, and must thus find a delicate balance between enmeshment and distancing countertransferences, both of which can be elicited by particular parts of the personality that pull for either contact or distance (Steele et al., 2001).

Initial interventions, as stated above, are directed primarily toward ANPs. Within a skills-building approach, the first interventions are of a psychoeducational nature. Basic information should be shared about therapy, treatment process, parameters of therapeutic boundaries, treatment goals, the patient's symptoms and disorders, informed consent, and collaboration and cooperation between therapist and patient, among others. In other words, the therapeutic process should not remain mysterious or unexplained to the patient, so that s/he may be an active participant with encouraged collaboration with the therapist. Such information will also be of relational value, as the patient begins to experience the therapist as someone who offers helpful information rather than as a withholding authority figure.

One significant way in which patients avoid contact with the therapist is to not be mentally present through extreme retraction of the field of consciousness, lowering of the level of consciousness, and depersonalization. Assisting a patient to remain aware of and to stay in the present is a constant effort for the therapist (Van der Hart \& Steele, 1997). Many patients give idiosyncratic clues about lack of presence, and some are quite obvious, such as "spacing out" and non-responsiveness. Helping the patient tolerate the present will allow for more reality testing regarding the therapist, as well as time for safe internal work to be accomplished.

The consistency and predictability of the therapist is essential in reducing the phobia of attachment and attachment loss, and also in supporting the patient's growing integrative capacity. Although constant availability is neither possible nor helpful, predictable availability is highly recommended (Gunderson, 1996). The patient should have a clear understanding of the extent and limitations of outside contacts 
such as crisis telephone calls with the therapist, and have access to crisis support in the event of the therapist's absence.

\section{Overcoming the Phobia of Mental Contents}

Verbal and nonverbal empathic attunement to the patient's feelings and distress is vital to building relationship, provides an appropriate model for internal empathy, and enhances motivation to experience feared and avoided mental contents. The therapist should first help the patient become aware of fears about mental contents and work through them, and only then assist the patient to become aware of, experience, and express mental contents (e.g., McCullough et al., 2003). Patients learn experientially that their internal mental contents (feelings, wishes, needs, fantasies, dissociative parts of the personality) can be accepted by another and, as importantly, by themselves.

Psychoeducation regarding mental contents and their level of reality must be constantly reinforced. For example, many patients cannot tell the difference between feeling and behavior; thus, if they feel angry, they fear they will act in uncontrollable rage, thereby increasing aversion to feelings, wishes, fantasies, etc. The therapist must reinforce that mental actions precede but do not necessarily end with behavioral actions.

\section{Overcoming the Phobia of Dissociative Parts of the Personality}

This phobia constitutes a special subgroup of mental contents, since dissociative parts of the personality often contain aversive or ambivalent mental contents. It is useful to begin first to work with ANPs together (the parts that function in daily life), reducing their avoidance of one another. This will directly improve normal daily functioning and provide increased integrative capacity to eventually deal with EPs. In the meantime, psychoeducation regarding the defensive nature of EPs and functions of ANPs, and occasional interventions to support safe containment of EPs, will assist the ANP in feeling safer with these parts of the personality.

The therapist must be consciously aware of the avoidance of the ANPs for EPs, as premature attempts to engage EPs in working with the ANPs can evoke further avoidance by the ANP. It is thus crucial to assist the patient in striving for collaboration and cooperation among parts, which ultimately enhances the flexibility and stability of the whole personality by promoting better coordination of action systems. A most im- 
portant intervention is gradual introduction of dissociative parts to each other (i.e., reducing phobic avoidance and dissociation among parts of the personality regarding their very existence and their mental contents in Phase 1). This must first occur without sharing traumatic memories. Then, promotion of cooperation and empathy may occur over time. Techniques include strict management of arousal states during sessions, ideomotor finger signaling (e.g., Hammond \& Cheek, 1988), encouragement of all dissociative parts to "listen and watch" in therapy and in normal life, use of imaginary meeting rooms, practice of collaborative problem solving among dissociative parts, and practice and joint execution of tasks in daily life. There may also be a need to practice and jointly participate in more difficult situations, such as defense in the face of perceived or real threat. These measures gradually erode dissociative barriers in a safe manner and raise integrative capacity.

There are two particular and related types of EPs that should receive special focus in Phase 1: aggressive and persecutory ones. Both are fixated in the protective "fight" defensive subsystem, and attempt to manage the difficult emotions of rage and anger related to feelings of loss, helplessness, despair, hurt, terror, or shame (Van der Hart et al., 1998). These EPs must be addressed early in therapy to provide adequate stabilization and to prepare for Phase 2 work. Often they are first indirectly addressed through the ANP who is in executive control. As it becomes more safe for the patient, these EPs may be addressed more directly (Van der Hart et al., 1998).

Such EPs are part of the emotional fight defensive subsystem, but have strong belief systems that serve as psychological defenses, such as the belief that one's self is strong, unhurt, and capable of carrying out overwhelming actions of rage and revenge. Aggressive EPs often experience, or at least present, their identity as strong and capable of protecting and fighting. Persecutory EPs tend to experience and present themselves as the original perpetrators engaged in the original traumatic actions.

Persecutory EPs, like their actual perpetrators, do not have regulatory skills to manage anger and rage, or the pain, shame, needs, and fear that underlie much of their hostility. They often desperately fight for control, attempting to silence fearful EPs, but doing so in ways that are imitations of the real perpetrator's actions and words that only heighten the fears of the other parts. Thus, a vicious cycle of fear and rage/internal punishment develops. Therefore, these parts must learn alternative ways to acting out rage and to cope with intense feelings.

In early treatment both types of EPs are usually quite active, creating instability for the patient and within treatment. The aggressive ones may 
make active contact with the therapist in direct verbal engagement regarding lack of trust and the shortcomings of the therapist. The persecutory ones may remain internal as hidden but terrifying, hostile and demeaning inner voices, often threatening the patient "not to tell" of the traumatizing events, or causing the patient to reexperience these events such that she becomes overwhelmed and avoidant of therapy.

Much work is needed to expand aggressive and persecutory EPs' retracted field of consciousness beyond defense tactics. The therapist must constantly explain the protective functions of aggressive parts of the personality to other parts in order to foster cooperation and empathy. The therapist must strive for direct, respectful, and empathic contact with the EP, paired with good limit setting on aggressive behaviors, postponement of destructive behaviors, and skills building (cf., Van der Hart et al., 1998).

When integrative capacity has been raised to the extent that the $\mathrm{ANP}(\mathrm{s})$ and key EPs are able to function more or less adequately in the present, can maintain attachment to the therapist, can tolerate and regulate mental contents, and have developed a degree of empathy and cooperation, Phase 2 may be initiated. Contraindications to Phase 2 would include the absence of the above, and also current and ongoing abuse; current acute external life crises or times when extra energy and focus is needed in normal life; extreme age, physical or terminal illness; psychosis; severe characterological problems that interfere with the basic therapy process; and uncontrolled switching among ANP and EPs (Boon, 1997; Kluft, 1997; Steele \& Colrain, 1990; Van der Hart \& Boon, 1997). These goals may be achieved rather quickly in high-functioning patients, but will be time-consuming (usually a number of years) in patients that are less functional. Although many of these goals may eventually be achieved within the group of patients with the least favorable prognosis, Phase 2 work usually continues to seriously destabilize such patients. In most of those extremely difficult cases, complete stabilization is not often achieved, and Phase 1 work remains the final goal of treatment. In all cases, patients should have informed choice about moving into Phase 2 treatment."

\section{PHASE 2: TREATMENT OF TRAUMATIC MEMORIES}

Major goals of Phase 2 work are synthesis and realization of traumatic memories among various parts of the personality, rendering structural dissociation unnecessary. The principal elements of the traumatic 
experience must be synthesized, shared among $\mathrm{ANP}(\mathrm{s})$ and $\mathrm{EP}(\mathrm{s})$, and shifted to a symbolic verbal account that is personified. Then mental and behavioral actions in the present can be predicated upon this new integration.

\section{Overcoming Phobias Related to Insecure Attachment to the Perpetrator(s)}

The chronic elicitation of alternating action systems of attachment and defense related to the same caretaker is the basis of insecure attachment patterns. Insecure attachment involves intense bonding and loyalty, with the belief that attachment to the perpetrator is a life and death matter. Behaviors related to insecure attachment are those associated with low integrative capacity: reflexive, emotive, impulsive, lacking in cognitive processing. They include clinging, maladaptive dependence, and submission when in contact with perpetrator, and inability to realize the dangers associated with the perpetrator (Steele et al., 2001). Many ANPs are insecurely attached to perpetrators.

With the exception of EPs that are attached to the perpetrator(s) via the action (sub)system of the attachment cry, EPs are not directed toward attachment but rather toward physical defense and recuperation. Therefore, initial interventions are directed toward eliminating the fixed nature of the defensive and recuperative system in these parts, rather than promotion of attachment with the therapist. First, all parts should begin to have a sense of being in the safe present, even though that may not directly interact with the therapist. But the therapist can "talk to" and "talk through" to these parts, encouraging them to "look and listen, feel and focus on the present, where no harm can come to you in this room." However, much work must occur with aggressive parts of the personality before they can actually protect with empathy and cooperation, as noted in Phase 1. The fight EP, for example, should also be aware of and learn to be supportive of the EP that is attached to caretakers that were abusive.

Flexibility thus gradually develops among previously rigidly fixated defensive parts of the personality. As a more fluid and less dissociative defensive system is developed, and as parts become better oriented in the present, there is less need for defensive action. At this point attachment to the therapist can be successfully accomplished in small steps. It is vital that the EPs and ANP(s) gradually also become more securely attached with each other. Otherwise, a fantasy of rescue by the therapist may intensify with the building alliance. 
It is of primary importance in this phase to identify and treat substitute beliefs (Janet, 1945) of various ANPs and EPs regarding the perpetrator, the trauma, and current life. These fantasies are low quality mental actions that are substitutes for constructive actions in the present. They often involve idealization of the caretaker/perpetrator and devaluation of self (including blame and shame for what happened), preserving a sense of an internal locus of control, thus avoiding extreme helplessness, but keeping the patient in a state of chaos and limited functioning in the present.

\section{Overcoming the Phobia of Traumatic Memory}

This is one of the most difficult phobias to overcome, requiring high and sustained integrative capacity from $\mathrm{ANP}(\mathrm{s})$ and $\mathrm{EP}(\mathrm{s})$. The careful pacing of such work and regulation of hyper and hypo-arousal will be crucial to success. Contraindications to initiation of this phase should be strictly followed. The lower the integrative capacity of the individual, the slower this step of treatment must occur, with frequent returns to Phase 1 interventions.

Traumatic memory is treated in several stages (Van der Hart et al., 1993): (1) preparation, in which careful planning occurs; (2) synthesis: the resolution of dissociation regarding components of traumatic memories, and a beginning narrative account that eventually includes all parts of the personality. Synthesis of particular memories, or portions of memories are planned events that occur within a session or series of sessions; and (3) realization, including increasing levels of personification and presentification. This last stage is much more process-oriented and will occur over a period of time. It is often a crucial missing link in the treatment of traumatic memories, as some therapists view the "retrieval" of memory as the end of the process, whereas in reality, it is merely the beginning of a difficult and longer course. Of prime importance is the inclusion of $\mathrm{ANP}(\mathrm{s})$ in this work, although there may be occasional times when synthesis and various levels of realization may first occur among EPs (e.g., when several defensive subsystems might be integrated prior to work with the ANP on realization of the trauma).

\section{Preparation}

Safety and prevention of hyper-or hypo-arousal should be ensured. If contraindications are heeded and preparation is thorough, negative reactions are less likely. At times, it is helpful to arrange for someone to 
drive the patient home after a planned synthesis session, for support in the aftermath of the synthesis. It may be necessary for the patient to take time off from work or other obligations. But ideally, the patient should be able to continue to function in daily life, as this indicates a strong integrative capacity. Planned extended sessions may be helpful, not to increase intensity and duration of experiences, but rather to more slowly titrate traumatic experiences, and to give the patient plenty of time to become regrounded and fully re-oriented to the present before leaving session. The patient should have a thorough understanding of the purposes and experience of integrating traumatic memories. Hypnosis may be used to control and support this aspect of the process, but only if the therapist is well-trained, informed consent has been given, and the patient is accustomed to its formal use.

During preparation it is helpful, if possible, for the therapist to first have some awareness of basic content of the traumatizing event, including its beginning and end. Being aware of the beginning and end of the traumatizing events prevents that the patient from getting "stuck in the middle" during synthesis. This is best accomplished with those dissociative parts (e.g., observing parts) that can do so without going into an uncontrolled reexperience of the traumatizing event. This means that parts that are not yet ready to listen in should withdraw to their safe places. Apart from content, the planning focuses on the question of which parts should initially participate (i.e., one or more of the parts keeping aspects of the traumatic memory and parts that can fulfill a helping role) such as offering courage, structure or comfort-during or directly after the synthesis.

There are many patients for whom such observing parts are not available or who are unable to contain affect adequately. Such patients can be prepared by helping all parts explore the worst case possibilities (e.g., "What is the worst thing that you could imagine you might have to deal with in regards to what you remember? and "If that happened, how could we both help you best deal with it?"; "What are some other things you might find difficult to cope with?").

Many cognitive errors and distortions, including substitute beliefs, should have been already identified and corrected, but some are only open to modification after synthesis. In addition to the existence of conscious cognitive errors, the trauma is embedded in context-specific beliefs and experiences, many of which are dissociated in EPs. These are called fixed ideas (idées fixes; Janet, 1894, 1898), or thoughts or mental images which take on exaggerated proportions, have a high emotional 
charge, and are dissociated from the ANP. These ideas manifest in flashbacks or intrusive thoughts (reexperiences).

\section{Synthesis}

The essence of synthesis is that the therapist guides the patient (or particular parts of the personality) through a series of short intensive experiences in which dissociated aspects of the traumatic memory are shared among parts. Synthesis is an effort of collaborative and controlled reactivation by the patient and the therapist. There are several ways of approaching synthesis, depending on the skills of the therapist and the needs of the individual patient. Some patients work most effectively by synthesizing memories with certain parts present and others in a safe place and not attending to the synthesis, while others find it more effective to synthesize with all parts present at a given time. Some synthesis may occur outside sessions, depending on the integrative capacity of the individual. It is essential to individualize the process of working with traumatic memories.

Not each and every detail of the trauma need be shared. What is essential to share are the so-called pathogenic kernels (Van der Hart \& Op den Velde, 1995) (i.e., the most threatening aspects of a traumatic experience, those that the patient wants to avoid at all costs). In many patients sufficient integrative capacity can be achieved such that the traumatic experience can be shared throughout the entire personality at once. Other times it may be necessary to work with smaller groups of parts in a graduated manner. If the latter is necessary, there should be discussion and agreement between the patient and therapist regarding which life areas, or action systems (e.g., work, parenting) and related parts of the personality should be protected from the current experience of synthesis.

For synthesis to succeed, it is essential that the level of arousal is controlled; panic and re-dissociation of the traumatic memory should be prevented. To this end, the therapist should explain that the traumatic memory need not be re-experienced as the original overwhelming event (i.e., it need not be relived). Instead, arousal may be modulated, for instance, to a degree of " 3 " on a scale of " 1 " to " 5 ." Strenuous and consistent efforts by the therapist and patient to keep the patient in the present and connected to the therapist are essential to the success of synthesis. In terms of behavior therapy, the prerequisite to synthesis is a combination of graduated exposure and prevention of pathological avoidance responses, including continued structural dissociation and prevention of 
pathological avoidance responses that maintain structural dissociation (Nijenhuis, 1994). Although some authors in the dissociative disorders field use expressions such as controlled abreaction or abreactive work to describe this process (e.g., Fine, 1993; Kluft, 1994a), synthesis should certainly not be misunderstood as a process meant for the uncontrolled expression of vehement emotions, as referred to in the term "abreaction" (cf. Van der Hart \& Brown, 1992, for a critical analysis).

There are many variants of synthesis. For example, while Van der Hart et al. (1993) describe a fast and comprehensive version in a single session, others have described a much more gradual approach (i.e., fractionated synthesis) in which the synthesis is divided in a number of smaller steps, which may encompass several or even many sessions (Fine, 1993; Kluft, 1994a; Van der Hart et al., 1993). Titrated synthesis may also occur with the use of EMDR and ample application of the SUDS scale during the process (e.g., Gelinas, 2003; Twombly, 2000). Actually, use of the SUDS scale is helpful even without EMDR. However, given the fact that EMDR is such a powerful and potentially destabilizing technique, it cannot be overstated that it should be used strictly within a context of containment, and only by well-trained clinicians familiar with treatment of dissociative disorder patients. Fractionated synthesis often can be applied when a fast and comprehensive approach would tax the patient's integrative capacity too much.

In general, any unshared material remaining after a synthesis session should be dealt with in a next session, or soon thereafter, and precautions should be taken that these remaining aspects of the traumatic memory do not overwhelm the patient in the meantime. However, it is often useful to have more cognitive processing sessions interspersed between synthesis sessions, as there needs to be time and support to personalize and fully realize the material. Hypnotic techniques or imagery such as putting these remainders in an imaginary safe space can be very helpful.

\section{Realization}

Synthesis alone is insufficient for integration. The traumatic memory must become a fully narrative autobiographical memory (i.e., it must be personalized and fully realized). A major difficulty is often encountered in helping the individual as ANP to fully realize his or her history, in spite of being aware of it. The ANP must be able to gradually become less avoidant and more accepting of EPs, fully owning past experiences, 
making a narrative account of the traumatic experience without dissociating any longer.

Once enough work has been done in Phase 2 to allow the patient to have gained higher overall integrative capacity, and the phobia of traumatic memory is no longer in the foreground, Phase 3 work can be initiated. Generally there is rather spontaneous movement back and forth into Phase 3, taking place when the patient begins to initiate exploration of Phase 3 issues.

\section{TREATMENT PHASE 3: \\ PERSONALITY INTEGRATION AND REHABILITATION}

Extensive focus on Phase 3 work is often absent in the literature (but see Kluft, 1993b), as though only Phases 1 and 2 were important. There is also the persisting myth among patients and some clinicians that remembering the traumatic experience is sufficient for healing. In fact, Phase 3 may contain some of the most difficult work yet (Van der Hart et al., 1993); painful grief work that is necessary for deepening realization to occur, relinquishment of strongly held substitute beliefs, and the struggle to engage in the world with new coping skills that require high degrees of sustained mental effort (i.e., increasing levels of personification and presentification, and a widening field of consciousness). The patient who cannot successfully complete Phase 3 work often continues to have difficulty with normal life, despite significant relief from traumatic intrusions.

Phase 3 often involves deeper and more involved work related to severe developmental neglect suffered by the patient, since increasing attempts to live normal life often highlight less obvious deficits related to action systems that were not developed adaptively. Severely traumatized patients persist in a tendency to dissociate under stress, and are accustomed to narrow fields and sometimes low levels of consciousness. Continued relapse prevention, including stress inoculation and self-care activities (deterrence of dissociation), and widening of the field of consciousness are essential ongoing tasks in Phase 3.

Parts of the personality generally make a gradual move toward fusion with each other, becoming less distinct and autonomous as empathy, sharing, and more cooperative in daily life increases. There are several pathways to fusion following this gradual process: formal, planned fusion rituals, with or without hypnosis; spontaneous fusions immediately following synthesis; spontaneous fusions that occur outside of therapy; 
or gradual blendings of parts that become fusions naturalistically over time (e.g., Kluft, 1993b). Therapeutic work needs to continue to support these integrative steps, which may be disrupted by crises or the emergence of new traumatic memories. In fact, during Phase 3 it is quite common for more dissociated traumatic material to emerge, as well as additional parts of the personality. This is partly because the integrative capacity rises and the patient is more able to tolerate previously dissociated experience. This is a normal and expected evolution of treatment, and during such times there will be a temporary return to Phase 1 and Phase 2 work.

Therapists and patients should not expect that full integration of the personality has occurred too quickly. As a general rule, what appears to be "final fusion" between dissociative parts of the personality is not the last one. Based on his observation of a large treatment cohort, Kluft (1993b) stated that only after 27 months of no further manifestations of dissociation may one safely assume that integration is indeed secure, indicating a need for thorough follow up.

The phobias addressed in Phase 3 involve living a normal life, relatively free of traumatic intrusion and dissociation.

\section{Overcoming the Phobia of Normal Life}

Previous to Phase 2 work, normal life often held any number of triggers, or conditioned stimuli, that evoked overwhelming reexperiences. Thus many aspects of life have been arduously avoided and subsequently constricted. Normal life also carries a requirement to adapt to and integrate a wide variety of complex and sometimes difficult experiences. This can be daunting to an individual whose life has been organized around restriction and avoidance.

Normal life must first be appraised for its level of actual normality (obviously, there is a wide range of what is considered "normal"), including what the patient wishes to achieve. It is imperative to determine if the patient has a relatively balanced life in terms of work, play, rest, and relationships, and that these experiences are meaningful and personalized. Often this is not the case, since balance in normal life requires high integrative capacity and flexibility and coordination among action systems. Although much integration among ANPs and EPs may have occurred by Phase 3, there remains the work of fully activating and refining action systems and their interdependence. For example, an ANP who was an excellent mother was able to successfully integrate several child EPs. However, neither ANP nor EPs had much experience 
with the exploratory and play action systems (although the ANP was quite adept in supporting her children in play and exploration as part of her care-taking functions). Thus there remained an absence in the patient's life of recreation, humor, and playfulness in relationship. These systems were progressively activated through psychoeducation, practice of increasingly prolonged and complex tasks (Van der Hart et al., 1989), observation of other people, and the gradual development of several friendships with people who were more adept in these areas, and at times, additional resolution of fixed ideas and traumatic memories.

Immersion in normal life often brings heightened joy and excitement with each new gain and positive experience. But simultaneously there occurs profound grief about missing out on normal life for so long. Patients can feel confused or ashamed of the duality of feelings evoked by healing, and should be helped to accept it. There is a strong realization of what has been lost or missing, not only during a traumatic childhood, but also in adulthood as a result of the cumulative miseries of a chronic dissociative disorder. Thus, grieving is an essential process during Phase 3. Grieving should be accompanied by strong awareness of the present (presentification), the ability to self-soothe and to take comfort in the new gains in life, and in connection from others. Otherwise the patient may become mired in despair, feeling increasingly isolated with unbearable loss. The therapist can play an essential role in successful grief work by empathically bearing witness to the patient's suffering (and subsequent healing), thus restoring the empathic connection with self, others, and the world that was lost during trauma (Herman, 1992; Laub \& Auerhahn, 1989; Van der Hart et al., 1993; Van der Hart \& Nijenhuis, 1999).

As all parts (ANPs and EPs), and thus all action systems become available in the present to work together cooperatively toward common goals, internal states become less conflicted and attention may be focused in adaptive ways on the present. Exposure to situations in which new adaptations and learning can occur is essential to resolving the phobia of normal life, but such experiences evoke yet another related phobia: that of healthy risk-taking and change.

\section{Overcoming the Phobia of Healthy Risk-Taking and Change}

Risk-taking and change are necessary for continued adaptation to current circumstances. Many traumatized patients express a fear of change in general, leading to a monotonous and restricted lifestyle, albeit chaotic at times, since chaos is familiar to most patients. Janet 
$(1903,1909)$ noted that one of the first difficulties to appear with lowering of integrative capacity was a phobia related to adapting to new situations. On more severe levels this can manifest in intense avoidance and fear of any internal or external change. This phobia is often particularly evident in certain ANPs.

Treatment consists of correcting substitute beliefs and fixed ideas regarding change (e.g., it is dangerous, is intolerable, will induce helplessness and incompetence). Traumatic memory resolution is essential, as the onset of change often evokes representations of the defensive system (EPs), which then intrude upon or deactivate ANPs. One patient made a very clear and concrete connection between her fear of any change and the onset of abuse: "When my father started having sex with me, everything changed. Change to me represents the most awful thing that could happen. Sex hurt, so change will hurt." Change is thus perceived as a severe threat. Practice, graduated exercises, increased awareness and personalization of safe changes that have occurred throughout therapy, and continued support for sustained mental effort related to change and risk are important interventions.

\section{Overcoming the Phobia of Intimacy}

Overcoming the phobia of intimacy is perhaps the pinnacle of successful treatment. It requires the integration of all action systems within the field of personal consciousness and the highest levels of sustained personification and presentification. For mature intimacy to occur one must have overcome phobias of internal states, of attachment, of traumatic memories, of risk-taking and change, and of normal life. Intimacy takes various forms, such as emotional, physical (non-sexual), and sexual. Phobias may be related to some or all of these forms.

To a large degree, the phobia of intimacy will have been addressed within the therapeutic relationship, which should offer the experience of secure attachment. However, overcoming the phobia of intimacy implies the realization that one's own capacity for intimacy is not limited to a relationship with a single individual (i.e., the therapist). For this realization to be fully integrated, intimacy must be experienced in less controlled situations (i.e., in the "real" world), with other individuals. The patient should be assisted in approaching it in a graduated manner; overcoming fear of emotional intimacy prior to physical and sexual intimacy, as the last two require the first to be in place. Usually there is extreme resistance to the experience of loss, an inevitable risk associated with intimacy. Increasing levels of presentification will prevent the 
patient from living in the perceived catastrophic future, full of unbearable loss, or in the past, in which relational loss or hurt was predominant. In addition, the patient must be able to tolerate in the present the very ordinary glitches and difficulties that arise within normal intimate relationships. This requires adequate conflict resolution skills, empathy, self-soothing, reflective thought rather than reflexive action, and the ability to distinguish gradations of difficulty in relationship, so that over or under-reaction does not occur.

Intimacy requires good limits and boundaries, both internal and relational. Patients generally have to learn the importance of personal boundaries, how and when to apply them, and how to respond effectively to others' boundaries without feeling rejected by recognizing that "good fences make good neighbors." Effective boundaries reduce fear of intimacy, giving some sense of personal control, and equalizing the balance of power in relationships.

At this point we reiterate that phase-oriented treatment is cyclical. Phase 3 work may open the door from time to time for further Phase 1 or 2 work. Once a patient begins to engage in new actions, such as entering an intimate sexual relationship, residual issues may emerge, as well as parts of the personality that have not been engaged sufficiently in treatment.

\section{CONCLUSION}

The theory of structural dissociation of the personality is rooted in late 19th and early 20th century views on dissociation and enriched by a wealth of recent research findings and clinical observations. It traverses the entire spectrum of trauma-related disorders. The theory serves as a heuristic for effective treatment and further research on dissication. In this article we focused on the treatment of trauma-related phobias in complex dissociative disorders. At the roots of these disorders is a chronic lack of integrative capacity that compromizes the adaptive quality of the survivor's mental and behavioral actions. In this context, survivors tend to develop a range of phobias that maintain or strengthen trauma-related structural dissociation of their personality. These phobias, proliferated most in the complex dissociative disorders, constitute a subgroup within the wider range of maladaptive action tendencies in chronically traumatized individuals. Therefore, therapists assist patients in correcting dysfunctional action tendencies, in developing adequate tendencies, and in overcoming their phobias. This work should 
allow patients to eventually synthesize and realize their traumatic memories and integrate their dissociative parts of the personality, while simultaneously adapt more effectively to the challenges of life.

The theory of structural dissociation and consistent clinical observations suggest that chronically traumatized patients can only achieve these goals in a gradual and phasic manner that in practice often takes the form of a recursive spiral (Courtois, 1999; Ford et al., in press). Thus, therapists only engage patients in therapeutic actions they can successfully initiate, execute and complete. Already noted by Janet, successes enhance survivors' integrative capacity, which allows them to develop somewhat higher-level mental and behavioral actions that can replace the phobic and dysfunctional substitute actions. These achievements boost survivors' integrative capacity further, which promotes still higher-level actions, etc.

We conceive the structural theory of dissociation of the personality as an integrative theory, allowing the use of innumerable interventions based on other theories, such as psychodynamic, object relations, cognitive behavioral, etc., to the degree that therapists follow the basic principles of treatment suggested by the theory. In other words, the theory of structural dissociation is compatible with, or complementary to much in other theories that guide effective treatment of patients with complex dissociative disorders. We believe that further understanding of and research on the theory of structural dissociation will enhance a more integrative understanding of the complex treatment issues with chronically traumatized individuals.

\section{REFERENCES}

Allen, J.G. (2001). Traumatic relationships and serious mental disorders. New York: John Wiley \& Sons.

American Psychiatric Association. (1994). Diagnostic and statistical manual of mental disorders, 4th ed. Washington, DC: Author.

Arnold, M.B. (1960). Emotion and personality (Two parts). New York: Columbia University Press.

Barach, P. (1991). Multiple personality disorder as an attachment disorder. Dissociation, 4, 117-123.

Barkes, J.H., Cosmides, L., \& Tooby, J. (1992). The adapted mind: Evolutionary psychology and the generation of culture. New York: Oxford University Press.

Becker-Blease, K.A., Deater-Deckard, K., Eley, T., Freyd, J.J., Stevenson, J., \& Plomin, R. (2004). A genetic analysis of individual differences in dissociative be- 
haviors in childhood and adolescence. Journal of Child Psychology and Psychiatry, 45, 522-532.

Benyakar, M., Kutz, I., Dasberg, H., \& Stern, M. (1989). The collapse of a structure: A structural approach to trauma. Journal of Traumatic Stress, 2, 431-450.

Blizard, R. (2001). Masochistic and sadistic ego states: Dissociative solutions to the dilemma of attachment to an abusive caretaker. Journal of Trauma \& Dissociation, 2(4), 37-58.

Blizard, R. (2003). Disorganized attachment, development of dissociated self states, and a relational approach to treatment. Journal of Trauma \& Dissociation, 4(3), 27-50.

Boon, S. (1997). The treatment of traumatic memories in DID: Indications and contra-indications. Dissociation, 10, 65-80.

Bowlby, J. (1969/1982). Attachment (2nd ed., vol. I). New York: Basic Books.

Bremner, J.D. (2003). Long-term effects of childhood abuse on brain and neurobiology. Child and Adolescent Psychiatric Clinics of North America, 12, 271-292.

Breuer, J., \& Freud, S. (1893-1895/1955). Studies on hysteria (Vol. 2). London: Hogarth Press.

Brewin, C.R. (2003). Posttraumatic stress disorder: Malady or myth? New Haven: Yale University Press.

Brewin, C.R., Andrews, \& Valentine, J.D. (2000). Meta-analysis of risk-factors for posttraumatic stress disorder in trauma-exposed adults. Journal of Consulting and Clinical Psychology, 68, 748-766.

Brown, D.P., \& Fromm, E. (1986). Hypnotherapy and hypnoanalysis. Hillsdale, NJ: L. Erlbaum Associates.

Brown, D., Scheflin, A.W., \& Hammond, D.C. (1998). Memory, trauma treatment, and the law. New York: W.W. Norton \& Co.

Cardena, E. (1994). The domain of dissociation. In S. J. Lynn \& J. W. Rhue (Eds.), Dissociation: Clinical and theoretical perspectives (pp. 15-31). New York: Guilford Press.

Carlson, E.A. (1998). A prospective longitudinal study of disorganized/disoriented attachment. Child Development, 69, 1107-1128.

Cassidy, J. (1999). The nature of the child's ties. In J. Cassidy \& P.R. Shaver (Eds.), Handbook of attachment: Theory, research, and clinical applications (pp. 3-20). New York: Guilford Press.

Chu, J.A. (1998). Rebuilding shattered lives: The responsible treatment of complex posttraumatic stress and dissociative disorders. New York: Guilford Press.

Courtois, C. (1999). Recollections of sexual abuse: Treatment principles and guidelines. New York: W.W. Norton \& Co.

Dalenberg, C.J. (2000). Countertransference and the treatment of trauma. Washington, DC: American Psychological Association.

Davies, J.M., \& Frawley, M.G. (1994). The psychoanalytic treatment of adult survivors of childhood sexual abuse. New York: Basic Books.

DeBellis, M.D. (2001). Developmental traumatology: The psychobiological development of maltreated children and its implications for research, treatment, and policy. Development and Psychopathology, 13, 539-564. 
Fanselow, M.S., \& Lester, L.S. (1988). A functional behavioristic approach to aversively motivated behavior: Predatory imminence as a determinant of the topography of defensive behavior. In R.C. Bolles \& M.D. Beecher (Eds.), Evolution and learning (pp. 185-212). Hillsdale, NJ: Erlbaum.

Fine, C.G. (1993). A tactical integrationalist perspective on the treatment of multiple personality disorder. In R.P. Kluft \& C.G. Fine (Eds.), Clinical perspectives on multiple personality disorder (pp. 135-153). Washington, DC: American Psychiatric Press.

Fonagy, P., Gergely, G., Jurist, E.L., \& Target, M. (2002). Affect regulation, mentalization, and the development of the self. New York: Other Press.

Fonagy, P., \& Target, M. (1997). Attachment and reflective function: their role in self-organization. Developmental Psychopathology, 9, 679-700.

Ford, J.D., Courtois, C., Steele, K., Van der Hart, O., \& Nijenhuis, E.R.S. (in press). Treatment of complex posttraumatic self-dysregulation. Journal of Traumatic Stress.

Forrest, K.A. (2001). Toward an etiology of dissociative identity disorder: A neurodevelopmental approach. Consciousness and Cognition, 10, 259-293.

Freyd, J. J. (1996). Betrayal trauma: The logic of forgetting childhood abuse. Cambridge, MA: Cambridge University Press.

Frijda, N. (1986). The emotions. Cambridge: Cambridge University Press.

Gelinas, D.J. (2003). Integrating EMDR into phase-oriented treatment for trauma. Journal of Trauma \& Dissociation, 4(3), 91-135.

Glaser, D. (2000). Child abuse and neglect and the brain: A review. Journal of Child Psychology and Psychiatry, 41, 97-116.

Gold, S.N. (2000). Not trauma alone. Philadelphia: Brunner/Routledge.

Gould, J.L. (1982). Ethology: The mechanisms and evolution of behavior. New York: W.W. Norton \& Co.

Gunderson, J. (1996). The borderline patient's intolerance of aloneness: Insecure attachments and therapist availability. American Journal of Psychiatry, 153, 752758.

Hammond, D.C., \& Cheek, D.B. (1988). Ideomotor signaling: A method for rapid unconscious exploration. In D.C. Hammond (Ed.), Hypnotic induction and suggestion: An introductory manual (pp. 90-97). Des Plaines, IL: American Society of Clinical Hypnosis.

Herman, J.L. (1992). Trauma and recovery. New York: Basic Books.

Horevitz, R., \& Loewenstein, R.J. (1994). The rational treatment of multiple personality disorder. In S.J. Lynn \& J.W. Rhue (Eds.), Dissociation: Clinical and theoretical perspectives (pp. 289-316). New York: Guilford Press.

Huber, M. (1995). Multiple persönlichkeiten: Überlebenden extremer Gewalt [Multiple personalities: Survivors of extreme violence]. Frankfurt am Main: Fischer.

Hurley, S.L. (1998). Consciousness in action. Cambridge, MA: Harvard University Press.

Jackson, J.H. (1931/32). Selected writings of John Hughlings Jackson (Vol. 1 \& 2). London: Milford.

Janet, P. (1889). L'automatisme psychologique [Psychological automatism]. Paris: Félix Alcan. 
Janet, P. (1894). Histoire d'une idée fixe [History of a fixed idea]. Revue Philosophique, 37, 121-163.

Janet, P. (1898). Névroses et idées fixes [Neuroses and fixed ideas]. Paris: Félix Alcan.

Janet, P. (1903). Les obsessions et la psychasthénie [Obsessions and psychasthenia] (vol. 1). Paris: Félix Alcan.

Janet, P. (1904). L'amnésie et la dissociation des souvenirs par l'émotion [Amnesia and dissociation of memories through emotion]. Journal de Psychologie, 1, 417453.

Janet, P. (1909). Les névroses [The neuroses]. Paris: E. Flammarion.

Janet, P. (1919/25). Psychological healing. New York: Macmillan.

Janet, P. (1928a). L'évolution de la mémoire et de la notion du temps [The evolution of memory and the notion of time]. Paris: A Chahine.

Janet, P. (1928b). De l'angoisse à l'extase (vol. 2), Les sentiments fondamentaux [From agony to ecstasy (vol.2), The fundamental feelings]. Paris: Félix Alcan.

Janet, P. (1935). Réalisation et interpretation [Realization and interpretation]. Annales Médico-Psychologiques, 93, 329-366.

Janet, P. (1945). La croyance délirante [Delirious belief]. Schweizerische Zeitschrift für Psychologie, 4, 173-187.

Kardiner, A. (1941). The traumatic neuroses of war. New York: P. Hoeber.

Kihlstrom, J.F. (1994). One hundred years of hysteria. In S.J. Lynn \& J.W. Rhue (Eds.), Dissociation: Clinical and theoretical perspectives (pp. 365-395). New York: Guilford Press.

Kluft, R.P. (1993a). The initial stages of psychotherapy in the treatment of multiple personality disorder. Dissociation, 6, 145-161.

Kluft, R.P. (1993b). Clinical approaches to the integration of personalities. In R.P. Kluft \& C.G. Fine (Eds.), Clinical perspectives on the treatment of multiple personality disorder (pp. 101-133). Washington, DC: American Psychiatric Press.

Kluft, R.P. (1994a). Applications of hypnotic interventions. Hypnos: Journal of the European Society of Hypnosis, 21, 205-223.

Kluft, R.P. (1994b). Countertransference in the treatment of multiple personality disorder. In J.P. Wilson \& J.D. Lindy (Eds.), Countertransference in the treatment of PTSD (pp. 122-150). New York: Guilford Press.

Kluft, R P. (1994c). Treatment trajectories in multiple personality disorder. Dissociation, 7, 63-76.

Kluft, R.P. (1997). On the treatment of traumatic memories: Always? Never? Sometimes? Now? Later? Dissociation, 10, 80-90.

Kluft, R.P. (1999). An overview of the psychotherapy of dissociative identity disorder. American Journal of Psychotherapy, 53, 289-319.

Krystal, J.H., Bannett, A., Bremner, J.D., Southwick, S.M., \& Charney, D.S. (1996). Recent developments in the neurobiology of dissociation: Implications for posttraumatic stress disorder. In L. Michelson \& W. J. Ray (Eds.), Handbook of dissociation: Theoretical, empirical, and clinical perspectives (pp. 163-190). New York: Plenum Press.

Lang, P.J., Bradley, M.M., \& Cuthbert, B.N. (1998). Emotion, motivation, and anxiety: Brain mechanisms and psychophysiology. Biological Psychiatry, 44, 1248-1263. 
Laub, D., \& Auerhahn, N.C. (1989). Failed empathy: A central theme in the survivor's Holocaust experiences. Psychoanalytic Psychology, 6, 377-400.

Lichtenberg, J.D. (1990). On motivational systems. Journal of the American Psychoanalytic Association, 38, 517-518.

Lichtenberg, J.D., \& Kindler, A.R. (1994). A motivational systems approach to the clinical experience. Journal of the American Psychoanalytic Association, 42, 405420.

Linehan, M.M. (1993). Cognitive behavioral treatment of borderline personality disorder. New York: Guildford Press.

Liotti, G. (1999). Disorganization of attachment as a model for understanding dissociative psychopathology. In J. Solomon \& C. George (Eds.), Attachment disorganization, 297-317. New York: Guilford Press.

Loewenstein, R.J. (1993). Posttraumatic and dissociative aspects of transference and countertransference in the treatment of multiple personality disorder. In R.P. Kluft \& C.G. Fine (Eds.), Clinical perspectives on multiple personality disorder (pp. 51-85). Washington: American Psychiatric Press.

Lyons-Ruth, K. (2003). Dissociation and the parent-infant dialogue: A longitudinal perspective from attachment research. Journal of the American Psychoanalytic Association, 51, 883-911.

Marmar, C.R., Weiss, D.S., \& Metzler, T.J. (1998). Peritraumatic dissociation and posttraumatic stress disorder. In J.D. Bremner \& C.R. Marmar (Eds.), Trauma, memory, and dissociation (pp. 229-252). Washington, DC: American Psychiatric Press.

Marshall, R.D., Spitzer, R., \& Liebowitz, M.R. (1999). Review and critique of the new DSM-IV diagnosis of acute stress disorder. American Journal of Psychiatry, 156, 1677-1685.

McCullough, L., Kuhn, N., Andrews, S., Kaplan, A., Wolf, J., Hurley, C.L., \& Hurley, C. (2003). Treating affect phobia: A manual for short-term dynamic psychotherapy. New York: Guilford Press.

McDougall, W. (1926). An outline of abnormal psychology. London: Methuen.

McGloin, J.M., \& Widom, C.S. (2001). Resilience among abused and neglected children grown up. Development and Psychopathology, 13, 1021-1038.

Meares, R. (1999). The contribution of Hughlings Jackson to an understanding of dissociation. American Journal of Psychiatry, 156, 1850-1855.

Myers, C.S. (1940). Shell shock in France 1914-18. Cambridge, UK: Cambridge University Press.

Nijenhuis, E.R.S. (1994). Dissociatieve stoornissen en psychotrauma [Dissociative disorders and psychological trauma]. Houten: Bohn Stafleu Van Loghum.

Nijenhuis, E.R.S. (1999). Somatoform dissociation: Phenomena, measurement, and theoretical issues. Reprint: 2004, New York: W.W. Norton \& Co.

Nijenhuis, E.R.S., Spinhoven, P., Vanderlinden, J., Van Dyck, R., \& Van der Hart, O. (1998). Somatoform dissociative symptoms as related to animal defensive reactions to predatory threat and injury. Journal of Abnormal Psychology, 107, 63-73.

Nijenhuis, E.R.S., \& Van der Hart, O. (1999). Forgetting and reexperiencing trauma: From anesthesia to pain. In J. Goodwin \& R. Attias (Eds.), Splintered reflections: Images of the body in trauma (pp. 39-65). New York: Basic Books. 
Nijenhuis, E.R.S., Van der Hart, O., \& Steele, K. (2002). The emerging psychobiology of trauma-related dissociation and dissociative disorders. In H. D'haenen, J.A. den Boer \& P. Willner (Eds.), Biological psychiatry (pp. 1079-1098). Chicester, UK: John Wiley \& Sons.

Nijenhuis, E.R.S., Van der Hart, O., \& Steele, K. (2004a). Strukturelle Dissoziation der Persönlichkeitsstruktur: Traumatischer Upsprung, phobische Residuen [Structural dissociation of the personality: Traumatic origins, phobic maintenance]. In A. Hofmann, L. Reddemann, \& U. Gast (Eds.), Psychotherapie der dissoziativen Störungen [Psychotherapy of dissociative disorders] (pp.47-69). Stuttgart/New York: Georg Thieme Verlag.

Nijenhuis, E.R.S., Van der Hart, O., \& Steele, K. (2004b). Trauma-related structural dissociation of the personality. Retrieved, December 2004 from http://www.traumapages.com/nijenhuis-2004.htm

Ogawa, J.R., Sroufe, L.A., Weinfield, N.S., Carlson, E.A., \& Egeland, B. (1997). Development and the fragmented self: longitudinal study of dissociative symptomatology in a nonclinical sample. Development and Psychopathology, 9, 855-79.

Ogden, P., \& Minton, K. (2000). Sensorimotor psychotherapy: One method for processing trauma. Traumatology [On-line], 6(3), article 3. Retrieved December, 2004 from http://www.fsu.edu/ trauma/v6i3/v6i3a3.html.

Ozer, E.J., Best, S.R., Lipsey, T.L., \& Weiss, D.S. (2003). Predictors of posttraumatic stress disorder and symptoms in adults: a meta-analysis. Psychological Bulletin, 129, 52-73.

Panksepp, J. (1998). Affective neuroscience: The foundations of human and animal emotions. New York/Oxford: Oxford University Press.

Pearlman, L.A., \& Saakvitne, K.W. (1995). Trauma and the therapist: Countertransference and vicarious traumatization in psychotherapy with incest survivors. New York: W.W. Norton \& Co.

Perry, B.D., Pollard, R.A., Blakely, T.L., Baker, W.L., \& Vigilante, D. (1995). Childhood trauma, the neurobiology of adaptation, and "use dependent" development of the brain: How "states" become "traits." Infant Mental Health Journal, 16, 271291.

Putnam, F.W. (1997). Dissociation in children and adolescents: A developmental perspective. New York: Guilford Press.

Reinders, A.A., Nijenhuis, E.R.S., Paans, A.M., Korf, J., Willemsen, A.T., \& Den Boer, J.A. (2003). One brain, two selves. Neuroimage, 20, 2119-2125.

Reinders, A.A.T.S., Nijenhuis, E.R.S., Quak, J., Korf, J., Haaksma, J., Paans, A.J.M., Willemsen, A.T.M., \& Den Boer, J.A. (2003). Neural regions associated with the processing of neutral and trauma memory scripts by apparently normal and emotional parts of the personality in dissociative identity disorder. Manuscript submitted for publication.

Rothschild, B. (2000). The body remembers: The psychophysiology of trauma and trauma treatment. New York: W.W. Norton \& Co.

Schore, A.N. (2003). Affect dysregulation and disorders of the self. New York: W.W. Norton \& Co.

Siegel, D. (1999). The developing mind: Toward a neurobiology of interpersonal experience. New York: Guilford Press. 
Spiegel, D. (1990). Trauma, dissociation, and hypnosis. In R.P. Kluft (Ed.), Incest-related syndromes of adult psychopathology (1st ed., pp. 247-261). Washington: American Psychiatric Press.

Steele, K., \& Colrain, J. (1990). Abreactive work with sexual abuse survivors: Concepts and techniques. In M.A. Hunter (Ed.), The sexually abused male (vol. 2, pp. 1-55). Lexington, MA: Lexington Press.

Steele, K., Dorahy, M., Van der Hart, O., \& Nijenhuis, E.R.S. (in press). Dissociation and alterations in consciousness: Different but related concepts. In P. Dell \& J. O'Neil (Eds.), Dissociation and the dissociative disorders: DSM-V and beyond. Chicago: International Society for the Study of Dissociation.

Steele, K., Van der Hart, O., \& Nijenhuis, E.R.S. (2001). Dependency in the treatment of complex posttraumatic stress disorder and dissociative disorders. Journal of Trauma \& Dissociation, 2(4), 79-116.

Steele, K., Van der Hart, O., \& Nijenhuis, E.R.S. (2004). Allgemeine Behandlungsstrategien komplexer dissoziativer Störungen: Die Bewältigung traumabezogener Phobien [Phase-oriented treatment of complex dissociative disorders: Overcoming trauma-related phobias]. In A. Eckhart-Henn \& S.O. Hoffman (Eds.), Dissoziative Störungen des Bewustseins: Theorie, Symptomatik, Therapie [Dissociative disorders of consciousness: Theory, symptoms, therapy] (pp. 357-394). Stuttgart, Germany: Schattauer-Verlag

Steele, K., Van der Hart, O., \& Nijenhuis, E.R.S. (in press). The theory of trauma-related structural dissociation of the personality. In P. Dell \& J. O'Neil (Eds.), Dissociation and the dissociative disorders: DSM-V and beyond. Chicago: International Society for the Study of Dissociation.

Sudakov, K.V. (2004). Functional systems theory and the probabilistic prediction of behavior. Neuroscience, Behavior, and Physiology, 34, 505-507.

Twombly, J.H. (2000). Incorporating EMDR and EMDR adaptations into the treatment of clients with dissociative identity disorder. Journal of Trauma \& Dissociation, 1(2), 61-80.

Van der Hart, O. (Ed.) (1995). Trauma, dissociatie en hypnose [Trauma, dissociation, and hypnosis] (3rd ed.) Lisse, Netherlands: Swets \& Zeitlinger.

Van der Hart, O., \& Boon, S. (1997). Treatment strategies for complex dissociative disorders: Two Dutch case examples. Dissociation, 10, 157-165.

Van der Hart, O., \& Brown, P. (1992). Abreaction re-evaluated. Dissociation, 5, 127-138.

Van der Hart, O., \& Dorahy, M. (in press). Dissociation: History of a concept. In P. Dell \& J. O'Neil (Eds.), Dissociation and the dissociative disorders: DSM-V and beyond. Chicago: International Society for the Study of Dissociation.

Van der Hart, O., \& Nijenhuis. E.R.S. (1999). Bearing witness to uncorroborated trauma: The clinician's development of reflective belief. Professional Psychology: Research and Practice 30, 37-44.

Van der Hart, O., Nijenhuis, E.R.S., Steele, K., \& Brown, D. (2004). Trauma-related dissociation: Conceptual clarity lost and found. Australian and New Zealand Journal of Psychiatry, 38, 906-914.

Van der Hart, O., \& Op den Velde, W. (1995). Traumatische herinneringen [Traumatic memories]. In O. van der Hart (Ed.), Trauma, dissociatie en hypnose [Trauma, dis- 
sociation, and hypnosis] (3rd ed., pp. 79-102). Lisse, Netherlands: Swets \& Zeitlinger.

Van der Hart, O., \& Steele, K. (1997). Time distortions in dissociative identity disorder: Janetian concepts and treatment. Dissociation, 10, 91-103.

Van der Hart, O., \& Steele, K. (1999). Relieving or reliving childhood trauma? A commentary on Miltenburg and Singer (1997). Theory and Psychology, 9, 533-540.

Van der Hart, O., Steele, K., Boon, S., \& Brown, P. (1993). The treatment of traumatic memories: Synthesis, realization, and integration. Dissociation, 6, 162-180.

Van der Hart, O., Van der Kolk, B.A., \& Boon, S. (1998). Treatment of dissociative disorders. In J.D. Bremner \& C.R. Marmar (Eds.), Trauma, memory, and dissociation (pp. 253-283). Washington, DC: American Psychiatric Press.

Van der Hart, O., Van Dijke, A., Van Son, M., \& Steele, K. (2000). Somatoform dissociation in traumatized World War I combat soldiers: A neglected clinical heritage. Journal of Trauma \& Dissociation, 1(4), 33-66.

Van der Kolk, B.A. (2003). The neurobiology of childhood trauma and abuse. Child \& Adolescent Psychiatric Clinics of North America, 12, 293-317.

Van der Kolk, B.A., \& Fisler, R. (1995). Dissociation and the fragmentary nature of traumatic memories: Overview and exploratory study. Journal of Traumatic Stress, $8,505-525$

Van der Kolk, B.A., \& Van der Hart, O. (1991). The intrusive past: The flexibility of memory and the engraving of trauma. American Imago, 48, 425-445.

Wilson, J.P., \& Lindy, J.D. (Eds.) (1994). Countertransference in the treatment of PTSD. New York: Guilford Press.

Wilson, J.P., \& Thomas, R.B. (2004). Empathy in the treatment of trauma and PTSD. New York: Brunner-Routledge.

Wolf, D.P. (1990). Being of several minds: Voices and versions of the self in early childhood. In D. Cicchetti \& M. Beeghly (Eds.), The self in transition: Infancy to childhood (pp. 183-212). Chicago: The Chicago University Press.

Wolff, P.H. (1987). The development of behavioral states and the expression of emotions in early childhood. Chicago: University of Chicago Press.

RECEIVED: 8/26/04

REVISED: $12 / 10 / 04$

ACCEPTED: $12 / 10 / 04$ 